\title{
Ownership, technology gap and technical efficiency of small and medium manufacturing firms in Vietnam: A stochastic meta frontier approach
}

\author{
Thi Minh Nguyena, Quoc Hoi Le ${ }^{a^{*}}$, Thi Van Hoa Trana, and Minh Ngoc Nguyen ${ }^{a}$
}

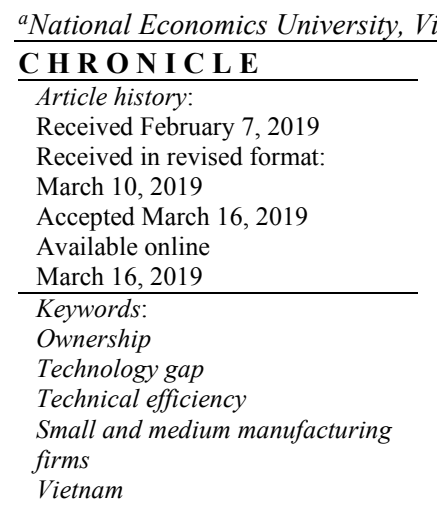

\begin{abstract}
A B S T R A C T
The ownership - efficiency relationship in a firm has always been an important topic. In this paper, we focus on the state owned versus non-state-owned status of Vietnamese manufacturing firms, to shed light into the relationship between these two variables when using a more stateof-the-art method as a stochastic meta-frontier method. Applying the method for two periods: one during the global economic crisis and the other after the end of the crisis, the study determines that in both periods, there was a strong evidence that non-state-owned firms performed much better than state owned counterpart. We also found that the difference became even larger during the harsh time and sub-industries with non-state-owned firms could outperform the state-owned firms, significantly.
\end{abstract}

\section{Introduction}

Vietnam is on the way towards to a more market-oriented economy. From the legal perspective, the Enterprise Law 2005 and more recently the Enterprise Law 2014 help to reduce the difference in the ways state owned enterprises (SOE) and non-SOE are treated by law. From the practical perspective, more enterprises have been privatized and that makes the private sector become more important part of the economy. However, the difference still exists, in which SOE are regarded as less efficient despite the fact that they get more preferential treatments compared with their non-SOE counterparts.

With the growing role of the private sector in the economy, a question remains is how the non-SOE firms perform compared with the SOE counterparts. On one hand, non-SOE firms do not have serious conflict of interest as in SOE firms, people who control the right of the firms may have not cash flow right at all. As such, non-SOE firms may be more flexible and have more incentive to take risk than SOE firms. Therefore, we may expect that the variation in firms' performance among non-SOE firms would be higher than that among SOE firms. As such, we would observe a technology gap between the production frontiers of the two groups, and the difference in efficiency as well. As technical efficiency

* Corresponding author.

E-mail address: hoilq@neu.edu.vn (Q.H. Le)

(C) 2019 by the authors; licensee Growing Science, Canada. doi: $10.5267 /$ j.dsl.2019.3.002 
is an important determinant of a firm's competitiveness, studies about firms' technical efficiency are rich and still growing. The studies often use different approaches, either parametric, non-parametric, or semi-parametric approaches. The non-parametric approaches are originally based on the Data Envelopment Analysis (DEA) method proposed by Charnes et al. (1978) from the idea of Farrell (1957). This method was used extensively in studies about firm's technical efficiency. However, when applied to different sets of data - the same industry for different economies or different sub industries in the same economy - the use of DEA to estimate firms' technical efficiency could be unjustified. As different sets of firms may use different sets of technology (Hayami, 1969) which cannot be described by the same set of parameters of the problem. In addition, the meta-DEA method proposed by Battese et al. (2004) and O'Donnell et al. (2008) has been extensively used to solve for efficiency measurement. Since then, the method has been applied in various studies (e.g. Goyal et al., 2018; Hafezalkotob et al., 2015; Naceur et al., 2011).

Another line of studies is to use the parametric approaches, which are originally based on stochastic frontier analysis (SPA), proposed simultaneously by Aigner et al. (1977) and Meeusen and Van den Broeck (1977). The idea of the SFA is that, firms are no longer assumed to be at their most efficient, hence the inefficient component should be added in the production function. The inefficient component of a firm is measured as the distance between the firm output and the output of the most efficient firm using the same bundle of input (for the SFA with the production function, and the same idea for the SFA with the cost function). Wang and Wong (2016), for example, used SFA to study the technical efficiency of Chinese manufacturing firms. Using a set of 12000 firms, they found that foreign direct investment (FDI) would not create the horizontal effect, i.e. the presence of FDI firms would not improve technical efficiency of the firms in the same industry. They also found that FDI had a mixed vertical effect and could improve the technical efficiency for the firms in upstream industries but not for the firms in downstream industries.

In Vietnam, there have been also many studies about technical efficiency, (see Ho, 2016; Nguyen; 2005, for example). These studies used normal DEA and SFA methods, hence may suffer from the mentioned above problem. Our study differs the previous works: first, we use the state-of-art method and focus on ownership in particular; secondly, we compare the situation in the time of economic crisis (2011) and when the crisis was over (2016). As such, we hope that the paper can bring about some insight into the existing literature. The structure of the paper is as followed: the following section will briefly introduce the methodology, the next section presents our model and estimated result, and the last section presents the conclusion to summarize the contribution of the paper.

\section{Methodology}

This section briefly presents the method used in this study, which is Stochastic Meta - frontier- analysis. We start by introducing the SFA approach and then move to the Stochastic Meta Frontier analysis.

\subsection{The SFA approach}

In the SFA approach, the production function of a firm can be expressed as (Aigner et al, 1977):

$$
y=\mathrm{f}(\mathrm{x}, \beta) \cdot e^{u} \cdot \mathrm{e}^{v}
$$

where $y$ represents the output, $x$ denotes the vector of inputs, $\beta$ is associated with the vector of parameters to be estimated; $v$ is the normal random error, which is assumed to be independent, identically distributed, and $u$ reflects the firm's inefficiency. In the setup, $u$ is assumed to be independent from $v$ and $u$ is non-positive and follows some specific distribution. It can be seen from Eq. (1) that if all firms are efficient then $u=0$. So normal practice of estimating the input shares is a special case of Eq. (1) when assuming that the production is efficient. Technical efficiency of firm $i$ can be calculated as:

$$
T E_{i}=\frac{y_{i}}{f\left(x_{i}, \beta\right) e^{v}}=e^{u_{i}}
$$


The TE of firm $i$ lets us know how much output of the firm could be produced using the same amount of inputs when the firm works, efficiently. In practice, the function $\mathrm{f}($.$) can take a common Cobb-$ Douglas form, and Eq. (1) can be expressed as:

$$
\ln (\mathrm{y})=\alpha_{0}+\alpha_{1} \ln \left(x_{1}\right)+. .+\alpha_{k} \ln \left(x_{k}\right)+v-u
$$

or translog form as:

$$
\ln (\mathrm{y})=\alpha_{0}+\alpha_{1} \ln \left(x_{1}\right)+. .+\alpha_{k} \ln \left(x_{k}\right)+\sum_{i>=j} \ln \left(x_{i}\right) \ln \left(x_{j}\right)+v-u
$$

The model can be estimated using maximum likelihood (ML) method with $v$ following a Normal, and $u$ follow either half-normal, exponential, or truncated normal distribution.

\subsection{Meta-SFA approach}

The above method is appropriate if all firms choose the same technology. However, in practice, firms may choose different technologies, depending on resource endowment, for instance. Hence if the firms in study are clustery heterogenous in their chosen technology, the meta production approach would be more appropriate. In that case, the production function of firm $i$ in group $j$ can be stated as follows,

$$
y_{i}^{j}=\mathrm{f}^{j}\left(\mathrm{x}_{i}, \alpha^{j}\right) \cdot e^{u_{i, j}} \cdot \mathrm{e}^{v_{i, j}} .
$$

Hence the technical efficiency for firm $i$ in group $j$ is as follows,

$$
T E_{i}^{j}=e^{u_{i, j}} \text {. }
$$

The meta frontier production function for all $M$ groups is also expressed as follows,

$$
f^{j}\left(x_{i}^{j}, \alpha^{j}\right)=f^{T}\left(x_{i}^{j}, \alpha^{j}\right) e^{-u_{i j}^{T}} \text {. }
$$

In $f^{T}($.$) is the production frontier for all groups, U_{i, j}^{T}$ indicates the difference in the frontier of each group to the frontier of all groups. Hence the ratio $\frac{f^{j}\left(x_{i, j}\right)}{f^{T}\left(x_{i, j}\right)}=\mathrm{e}^{-u_{i, j}^{M}}$ measures the technology gap ratio $T G R_{i, j}$ between the technology of the firm $i$ in group $j$ and the best technology for all groups. The metatechnical efficiency, measures the distance between the actual output of firm $i$ group $j$ and the metafrontier production function, $M T E_{i j}$ can be written as:

$$
M T E_{i, j}=T E_{i, j} x T G R_{i, j} .
$$

\section{The estimation}

Huang et al. (2014) proposed a method to estimate meta-technical efficiency MTE and technical gap ratio (TGR) as followed:

The first step: This step will use the mentioned above SFA method to estimate the frontier for each group to get $\hat{f_{j}}\left(x_{i, j}\right)$ using Eq. (2). This step will also produce technical efficiency for each firm, $T E_{i}^{j}$ Second step: In this step, the estimated group frontier in the first step will be used to estimate the metafrontier for the whole firms using Eq. (3), in which the $f_{j}\left(x_{i, j}\right)$ will be replaced by $\hat{f}_{j}\left(x_{i, j}\right)$. This step also helps to estimate TGR for each firm. 


\section{Data and empirical results}

\subsection{Data and variable description}

The data used in this study is taken from the enterprises census data set, conducted by the GSO every year since 1991. We focus on manufacturing firms in several sub-industries, including: food processing, weaving, clothing, chemistry, and electronics (other sub-industries like: tobacco, drinking, wood processing are not included as they are quite specific in technology as well as condition for production). In total, we have 17186 firms for analysis. Following the literature in technical efficiency, we include the following variables for the estimation of the meta-frontier technical efficiency and technology gap:

Table 1

Description of variables

\begin{tabular}{|c|c|c|}
\hline Variables & Notation & Roles \\
\hline Total output & $\mathrm{y}$ & Output variable MSFA \\
\hline Capital & $\mathrm{k}$ & Input variable \\
\hline Labor & 1 & Input variable \\
\hline Other cost & cost & Input variable \\
\hline Industrial zone & Khu_cn & $\begin{array}{l}\text { Environment variable, showing the different in infrastructure for } \\
\text { production }\end{array}$ \\
\hline Capital intensity & $\mathrm{k}-1$ & $=\mathrm{K} / \mathrm{L}$, the capital intensity of firms \\
\hline Ownership & ownership & $=1$ for SOE firms, 2 for non-SOE firms \\
\hline
\end{tabular}

The basis descriptive statistics are reported in Table 2:

Table 2

Basic descriptive statistics

\begin{tabular}{lccccc}
\hline Variable & mean & min & max & sd & $\mathrm{N}$ \\
\hline Lny & 8.24 & -2.30 & 16.13 & 2.50 & 15480 \\
Lnl & 6.55 & -0.22 & 14.79 & 1.83 & 16009 \\
Lnk & 8.51 & -2.30 & 15.44 & 1.82 & 16200 \\
Lncost & 5.97 & -2.30 & 15.83 & 2.40 & 16371 \\
co_khucn & 0.11 & 0.00 & 1.00 & 0.32 & 17186 \\
Lnkk & 19.83 & 16.89 & 19.93 & 0.51 & 17186 \\
Ownership & 1.98 & 1.00 & 2.00 & 0.18 & 17186 \\
\hline
\end{tabular}

Source: calculated from enterprise census

\subsection{Technical efficiency and technology gap between SOE and non-SOE firms}

In this part, we are going to estimate technical efficiency and technology gap ratio between two groups: SOE firms and non-SOE firms. We implement the estimation for two years: year 2011, reflecting the time of economic crisis, and year 2016, the time when the crisis was over.

LR test shows that the translog function form was more appropriate than the Cobb- Douglas form (see appendix for the test result)

$\ln y=\beta_{0}+\beta_{1} \ln k+\beta_{2} \ln l+\beta_{3} \ln \cos t+\beta_{4}(\ln k)^{2}+\beta_{5}(\ln 1)^{2}+\chi_{6}(\operatorname{lncost})^{2}+\beta_{7} \ln \operatorname{cost} \cdot \ln \mathrm{k}+\beta_{8} \ln \cos t+(v-u)$ Here $y$ represents the output while $k$ and $l$ are capital and labor, respectively. The prefix $l n$ means natural logarithm, for example, lny is the natural logarithm of $y$.

\section{Result for year 2016}

The MTE for SOE and for non-SOE are depicted in Fig. 1 


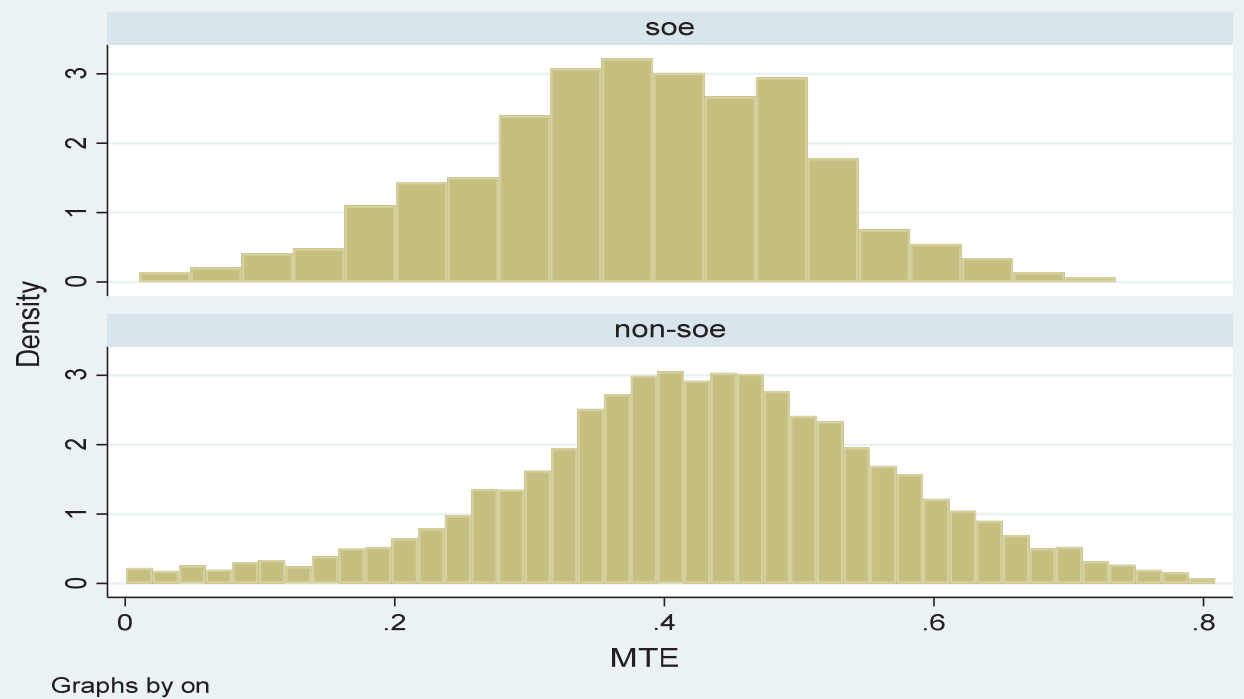

Fig. 1. The MTE for SOE and for non-SOE firms in 2016

From Fig. 1, it can be seen that the technical efficiency for both soe and non-soe firms are fairly low: around $50 \%$ of firms have MTE less than 0.5 . Table 3 shows the numbers in more details:

Table 3

MTE for SOE and for non-SOE in different percentiles, accumulated (in percentage)

\begin{tabular}{lcc}
\hline MTE & SOE & non-SOE \\
\hline $0-0.1$ & 1.6 & 2.3 \\
$0.1-0.2$ & 8.6 & 6.3 \\
$0.2-0.3$ & 23.5 & 16.8 \\
$0.3-0.4$ & 56.1 & 41.1 \\
$0.4-0.5$ & 84.3 & 70.3 \\
$0.5-0.6$ & 97.4 & 89.4 \\
$0.6-0.7$ & 99.7 & 97.5 \\
$0.8-0.9$ & 100.0 & 100.0 \\
$0.9-1.0$ & & 100 \\
\hline
\end{tabular}

Source: calculated from Enterprise census.

Table 3 shows that the number in column SOE is always greater than that in non-SOE column, except for the first value. It implies that the non-SOE firms perform better than SOE firms in terms of technical efficiency, for example, $97.4 \%$ of SOE firms have MTE $<0.6$, while the number for non-SOE firms is $89.4 \%$.

\section{Result for technology gap ratio}

For the technology gap ratio, we also wish to look at more details for each sub-industry. The technology gap ratios for SOE and non-SOE firms for each sub-industry are reported in Table 4.

\section{Table 4}

Technology gap ratio by ownership and by sub-industry.

\begin{tabular}{lccccccccccc}
\hline \multirow{2}{*}{ Interval } & \multicolumn{2}{c}{ Food } & \multicolumn{2}{c}{ Weaving } & \multicolumn{2}{c}{ Cloths } & \multicolumn{2}{c}{ chemical } & \multicolumn{2}{c}{ electronics } \\
\cline { 2 - 11 } & Soe & non-soe & soe & non-soe & soe & non-soe & soe & non-soe & soe & non-soe \\
\hline $0-0.2$ & 0.98 & 0.00 & 1.35 & 0.00 & 0.00 & 0.00 & 0.00 & 0.00 & 0.00 & 0.00 \\
$0.2-0.4$ & 7.35 & 0.00 & 9.46 & 0.00 & 4.00 & 0.00 & 21.15 & 0.00 & 14.29 & 0.00 \\
$0.4-0.6$ & 21.08 & 0.00 & 24.32 & 0.00 & 32.00 & 0.00 & 38.46 & 0.00 & 57.14 & 0.00 \\
$0.6-0.8$ & 40.69 & 10.20 & 36.49 & 15.35 & 40.00 & 3.85 & 30.77 & 19.22 & 28.57 & 35.90 \\
$0.8-1$ & 29.90 & 89.80 & 28.38 & 84.65 & 24.00 & 96.15 & 9.62 & 80.78 & 0.00 & 64.10 \\
\hline Total & 100 & 100 & 100 & 100 & 100 & 100 & 100 & 100 & 100 & 100 \\
\hline
\end{tabular}


Table 4 shows a salient feature about technology gap ratio between SOE and non -SOE firms: first, the non-SOEs perform better than SOEs for every sub-industry. For example, for food industry, only $29.9 \%$ of SOEs have TGR $>0.8$, while the number for non-SOEs is 89.8 . It means that most of the relatively best firms are non-SOEs and they are closer to the meta-production frontier.

\section{Result for year 2011}

To examine the relationship between firms' performance and ownership during the harsh time, we apply the same analysis for year 2011 .

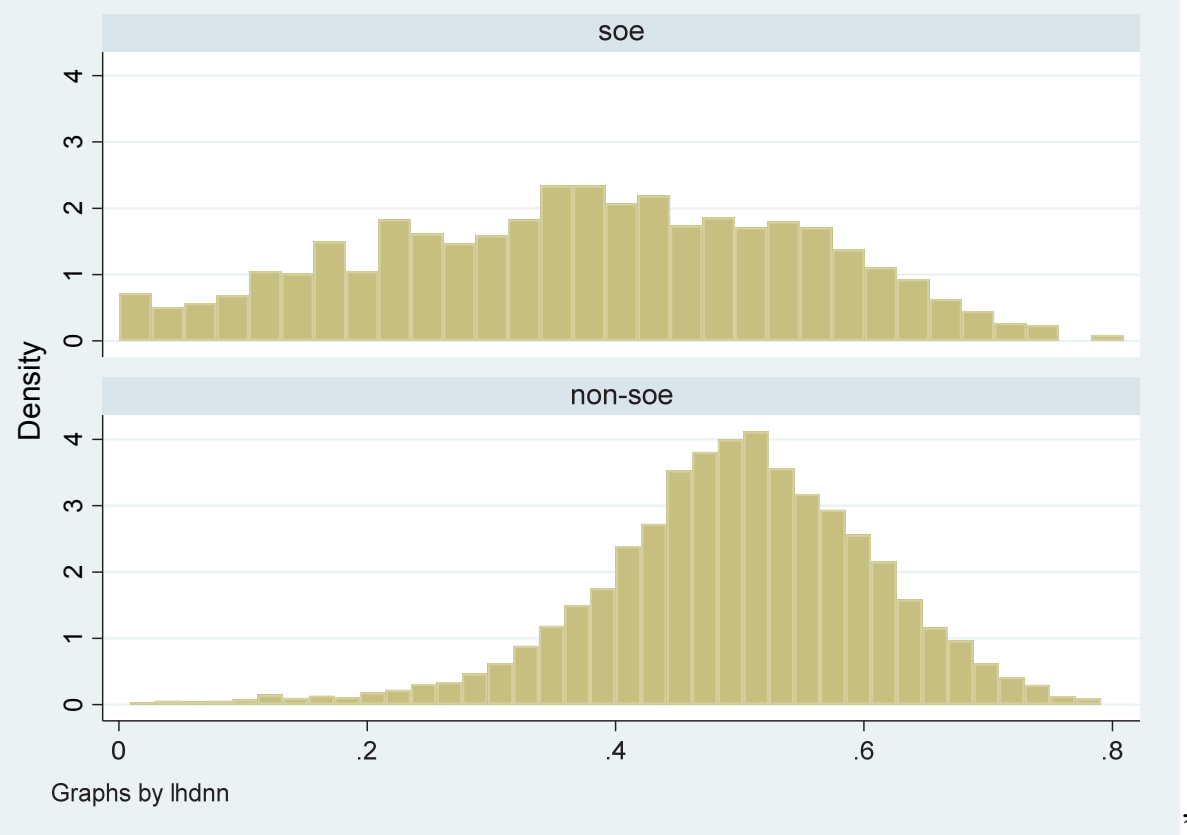

Fig. 2. The MTE for SOE and for non-SOE firms in 2011

It can be seen that in 2011, non-SOEs are much better than SOE: the ratio of firms with low TE is much higher with SOE firms than with non-SOE firms.

Table 5

MTE for SOE and for non-SOE in different percentiles 2011, accumulated (in percentage)

\begin{tabular}{llllllllll}
\hline MTE & $0-0.1$ & $0.1-0.2$ & $0.2-0.3$ & $0.3-0.4$ & $0.4-0.5$ & $0.5-0.6$ & $0.6-0.7$ & $0.8-0.9$ & $0.9-1$ \\
\hline Soe & 5.95 & 17.70 & 32.89 & 54.19 & 73.84 & 90.21 & 98.12 & 99.92 & 100 \\
non-soe & 0.46 & 1.76 & 4.94 & 17.11 & 50.02 & 83.27 & 97.61 & 100.00 & 100 \\
\hline \multicolumn{2}{l}{ rource: calculated from Enterprise census }
\end{tabular}

Source: calculated from Enterprise census

Table 5 also shows the same pattern as in year 2016, with stronger evidence that non-SOEs perform better than SOE firms. For example, $17.7 \%$ of SOE firms have MTE $<0.2$, while the number for nonSOE is only 1.76. The technology gap ratio by sub industry is illustrated in Table 6 .

Table 6

Technology gap ratio by ownership and by sub-industry, 2011

\begin{tabular}{|c|c|c|c|c|c|c|c|c|c|c|}
\hline \multirow{2}{*}{ Interval } & \multicolumn{2}{|c|}{ Food } & \multicolumn{2}{|c|}{ Weaving } & \multicolumn{2}{|c|}{ Cloths } & \multicolumn{2}{|c|}{ chemical } & \multicolumn{2}{|c|}{ electronics } \\
\hline & Soe & non-soe & soe & non-soe & soe & non-soe & soe & non-soe & soe & non-soe \\
\hline $0.2-0.4$ & 0.52 & 0.00 & 0.00 & 0.00 & 0.00 & 0.00 & 0.34 & 0.00 & 1.67 & 0.00 \\
\hline $0.4-0.6$ & 1.40 & 0.00 & 1.50 & 0.00 & 0.42 & 0.00 & 0.69 & 0.00 & 0.00 & 0.00 \\
\hline $0.6-0.8$ & 20.42 & 0.28 & 14.29 & 0.00 & 8.47 & 0.06 & 12.41 & 0.61 & 13.33 & 0.00 \\
\hline $0.8-1$ & 77.66 & 99.72 & 84.21 & 100 & 91.10 & 99.94 & 86.55 & 99.39 & 85.00 & 100 \\
\hline Sum & 100 & 100 & 100 & 100 & 100 & 100 & 100 & 100 & 100 & 100 \\
\hline
\end{tabular}


Source: calculated from Enterprise census

The numbers in Table 6 show the same story as in Table 4 for year 2016 with larger difference in TE between the two sectors.

\section{Conclusion}

This paper has been, by our knowledge, the first attempt to use stochastic-meta-frontier approach to study the relationship between ownership and technical efficiency - technology gap ratio for Vietnamese firms. More specifically, the paper has also made a comparison the relationship between two periods: in and after the impact of global economic crisis. Our result suggests that during the both periods, the non-SOEs performed much better than the SOEs counterpart. In fact, both technical efficiency and technology gap ratios were higher with non-SOE firms. More importantly, the gap was even larger in difficult time (year 2011). The performance gap may be because the non-SOE firms had more incentive to try harder and, at the same time, they were more flexible in making decision. The analysis of technology gap ratio has shown that in some sub industries, such as food industry, nonSOEs performed much better. Thus, the paper provides strong evidence about the relationship between ownership and firms' performance, and that in harsh time, non-SOE firms can cope with difficulty better than SOE firms.

\section{Acknowledgement}

The authors gratefully acknowledge financial support from National Foundation for Science \& Technology Development (Nafosted) grant 502.01-2017.13.

\section{References}

Aigner, D., Lovell, C. K., \& Schmidt, P. (1977). Formulation and estimation of stochastic frontier production function models. Journal of Econometrics, 6(1), 21-37.

Alem, H., Lien, G., Hardaker, J. B., \& Guttormsen, A. (2019). Regional differences in technical efficiency and technological gap of Norwegian dairy farms: a stochastic meta-frontier model. Applied Economics, 51(4), 409-421.

Battese, G. E., Rao, D. P., \& O'donnell, C. J. (2004). A metafrontier production function for estimation of technical efficiencies and technology gaps for firms operating under different technologies. Journal of Productivity Analysis, 21(1), 91-103.

Charnes, A., Cooper, W. W., \& Rhodes, E. (1978). Measuring the efficiency of decision making units. European journal of operational research, 2(6), 429-444.

Farrell, M. J. (1957). The measurement of productive efficiency. Journal of the Royal Statistical Society: Series A (General), 120(3), 253-281.

Goyal, J., Singh, R., Kaur, H., \& Singh, K. (2018). Intra-industry efficiency analysis of Indian textile industry: a meta-frontier DEA approach. International Journal of Law and Management, 60(6), 1448-1469.

Hafezalkotob, A., Haji-Sami, E., \& Omrani, H. (2015). Robust DEA under discrete uncertain data: a case study of Iranian electricity distribution companies. Journal of Industrial Engineering International, 11(2), 199-208.

Hayami, Y. (1969). Sources of agricultural productivity gap among selected countries. American Journal of Agricultural Economics, 51(3), 564-575.

Ho, D. B. (2016), Analysis of technical efficiency and productivity of general factors, Hanoi National University Publishing House (In Vietnamese).

Ho, D.B., Pham, V.M., Pham, V.T \& Truong, N.H (2018), A stochastic analysis of Vietnam bilateral trade efficiency. Journal of Economics and Development, 20(2), 50-64

Huang, C. J., Huang, T. H., \& Liu, N. H. (2014). A new approach to estimating the metafrontier production function based on a stochastic frontier framework. Journal of productivity Analysis, 42(3), 241-254. 
Le, V., Vu, X. B. B., \& Nghiem, S. (2018). Technical efficiency of small and medium manufacturing firms in Vietnam: A stochastic meta-frontier analysis". Economic Analysis and Policy, 59, 84-91.

Meeusen, W., \& van Den Broeck, J. (1977). Efficiency estimation from Cobb-Douglas production functions with composed error. International Economic Review, 18(2), 435-444.

Nguyen, K. M. (2005), Impact of technological progress on economic growth, Science and Technology Publishing House, Hanoi. (In Vietnamese)

Naceur, M. S. B., Casu, B., \& Ben-Khedhiri, H. (2011). What drives the performance of selected Mena banks? A+ L4624 meta-frontier analysis (No. 11-34). International Monetary Fund.

O’Donnell, C. J., Rao, D. P., \& Battese, G. E. (2008). Metafrontier frameworks for the study of firmlevel efficiencies and technology ratios. Empirical economics, 34(2), 231-255.

Wang, M., \& Wong, M. S. (2016). Effects of foreign direct investment on firm-level technical efficiency: stochastic frontier model evidence from Chinese manufacturing firms. Atlantic Economic Journal, 44(3), 335-361.

\section{Appendix 1}

LR test result

\begin{tabular}{|c|c|c|c|c|}
\hline \multicolumn{2}{|l|}{ Likelihood-ratio test } & LR chi2(3) & \multirow{2}{*}{$\begin{array}{l}= \\
=\end{array}$} & \multirow{2}{*}{$\begin{array}{l}9145.78 \\
0.0000\end{array}$} \\
\hline (Assumption: . nested in & b) & Prob $>$ chi2 & & \\
\hline Likelihood-ratio test & & LR chi2(3) & $=$ & 9145.78 \\
\hline (Assumption: . nested in b) & & Prob $>$ chi 2 & $=$ & 0.0000 \\
\hline \multicolumn{5}{|c|}{ Akaike's information criterion and Bayesian information criterion } \\
\hline Obs 11(null) & $11($ model $)$ & df & $\mathrm{IC}$ & $\mathrm{BIC}$ \\
\hline 373,212 & -577598.7 & 5 & 55207 & 1155262 \\
\hline 373,212 & -573025.9 & 11 & 46068 & 1146154 \\
\hline
\end{tabular}

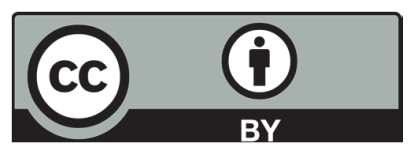

(C) 2019 by the authors; licensee Growing Science, Canada. This is an open access article distributed under the terms and conditions of the Creative Commons Attribution (CC-BY) license (http://creativecommons.org/licenses/by/4.0/). 